\title{
SOSIALISASI PERANAN EKOSISTEM MANGROVE PESISIR KUALA BUBON SEBAGAI UPAYA UNTUK MENUMBUHKAN KESADARAN SISWA/SISWI DI SEKOLAH SEKOLAH MENENGAH ATAS NEGERI 1 KECAMATAN SAMATIGA ACEH BARAT
}

\section{THE SOCIALIZATION OF THE ROLE OF MANGROVE ECOSYSTEM OF THE COAST OF KUALA BUBON AS THE EFFORT TO FOSTER THE STUDENT AWARENESS AT SENIOR HIGH SCHOOL 1 SAMATIGA DISTRICT WEST ACEH}

\author{
${ }^{1}$ Mohamad Gazali, ${ }^{2}$ Rina Syafitri \\ ${ }^{1}$ Prodi IImu Kelautan Fakultas Perikanan dan IImu Kelautan Universitas Teuku Umar \\ ${ }^{2}$ Prodi Agribisnis Fakultas Pertanian Universitas Teuku Umar \\ Korespondensi: mohamadgazali@utu.ac.id
}

\begin{abstract}
ABSTRAK
Mangrove memainkan peranan penting dalam melindungi pantai dari gelombang, angin dan badai. Tegakan mangrove dapat melindungi pemukiman, bangunan dan pertanian dari angin kencang atau intrusi air laut. Hutan mangrove yang merupakan green belt sudah banyak dihancurkan dan dieksploitasi secara illegal sehingga penetrasi gelombang mampu menghancurkan rumah-rumah, dan mengenangkan lahan pertanian. Pelaksanaan kegiatan ini telah dilaksanakan pada tanggal 5 November 2018 di SMAN 1 Samatiga Kecamatan Samatiga Kabupaten Aceh Barat Propinsi Aceh. Kegiatan kegiatan pengabdian kepada berupa sosialisasi peranan hutan mangrove kepada siswa/siswi SMAN 1 Samatiga dan kegiatan eksplorasi hutan mangrove bersama siswa/siswi. Metode pelaksanaan dengan menggunakan teknik penyuluhan secara langsung. Adapun tahapan pekerjaan dalam menyelesaikan permasalahan meliputi survey sekolah yang berdekatan dengan hutan mangrove, sosialisasi, kegiatan eksplorasi dan Monev. Materi sosialisasi peranan hutan mangrove di Sekolah Menengah Atas Negeri (SMAN 1) Samatiga. yang disampaikan berupa pengenalan spesies mangrove wilayah Samatiga dan Kegiatan survey lapangan serta eksplorasi ekosistem mangrove Hal ini bertujuan untuk memperkenal secara langsung tentang ekosistem mangrove kepada siswa/siswi.
\end{abstract}

Kata kunci : Sosialisasi, Hutan Mangrove, Kuala Bubon, Siswa/Siswi

\begin{abstract}
The mangrove play an important role in protection of beach from wave, wind and hurricane. The pole of mangrove can protect home, building and agriculture from bad wind or water intrution. Mangrove forest are green belt have already destroyed and exploited illegally. Thus the penetrate of wave can destroyed many home, land inundated the agriculture. The activities were conducted in 5 November 2018 in Senior High School 1 Samatiga. The empowerment activity including the socialization of mangrove forest role to student of SMAN 1 Samatiga. The conducting method with using extension directly. There are working stage to solve the problem including the survey, exploration activity, the socialization and MONEV. The material of the socialization that we deliver such as the introduction of mangrove species Samatiga area and survey activities as well as the exploration of mangrove ecosystem. The aims of this activity is to introduce directly regarding mangrove ecosystem to student.
\end{abstract}

Keywords : Socialization, mangrove forest, Kuala Bubon, student 


\section{PENDAHULUAN}

Indonesia dikarunia mangrove yang terluas di dunia dan juga memiliki keragaman hayati yang terbesar serta strukturnya paling bervariasi. Warisan alam yang sangat luar biasa ini memberikan tanggung jawab yang besar bagi masyarakat Indonesia untuk melestarikannya, sekaligus memberikan kesempatan yang berharga bagi mereka yang bermaksud mempelajari dan menikmati habitat ini. Mangrove merupakan ekosistem yang sangat produktif. Berbagai produk dari mangrove dapat dihasilkan baik secara langsung maupun tidak langsung, diantaranya: kayu bakar, bahan bangunan, keperluan rumah tangga, kertas, kulit, obat-obatan dan perikanan (Noor et al., 2006).

Mangrove memiliki peranan penting dalam melindungi pantai dari gelombang, angin dan badai. Tegakan mangrove dapat melindungi pemukiman, bangunan dan pertanian dari angin kencang atau intrusi air laut. Mangrove juga terbukti memainkan peran penting dalam melindungi pesisir dari gempuran badai. Dusun Tongke-tongke dan Pangasa, Sinjai, Sulawesi Selatan yang memiliki barisan mangrove yang tebal di pantai terlindung dari gelombang pasang (Tsunami) di pulau Flores pada akhir tahun 1993. Sedangkan beberapa dusun yang berbatasan dengan kedua dusun ini yang tidak mempunyai mangrove yang cukup tebal mengalami kerusakan yang cukup parah. Di Bangladesh, pada bulan Juni 1985 sebanyak 40.000 penduduk yang tinggal di pesisir dihantam badai. Mengetahui manfaat mangrove dalam menahan gempuran badai, pemerintah Bangladesh kemudian melakukan penanaman seluas 25.000 hektar areal pantai dengan vegetasi mangrove (Mann, 1982).

Tsunami pada tahun 2004 yang melanda di Aceh membuktikan bahwa hutan mangrove memainkan peranan penting dalam menyelamatkan hidup dan harta benda manusia. Hutan mangrove yang merupakan green belt sudah banyak dihancurkan dan dieksploitasi secara illegal sehingga penetrasi gelombang mampu menghancurkan rumah-rumah, mengenangkan lahan pertanian dan melibas orang-orang beserta mata pencaharian (Environmental Justice Foundation, 2004). Padahal hutan mangrove selain sebagai penghalang gelombang juga merupakan habitat beraneka ragam hewan yang mendiami zona hutan mangrove.

Pasca Tsunami, upaya menata ulang kawasan pantai tersebut telah diinisiasi oleh Badan Rehabilitasi dan Rekonstruksi Aceh Nias (BRR Aceh-Nias) dengan memperkenalkan konsep sabuk hijau (Green Belt) dimana pada awalnya ditetapkan zona yang berjarak 500 meter dari garis pantai tidak akan diperkenankan dibangun kembali pemukiman penduduk. Namun saat ini, konversi habitat mangrove menjadi lahan tambak, perumahan, tourist resort dan lahan pertanian sudah mengkhawatirkan. Sementara, reboisasi hutan mangrove yang sudah dilakukan oleh beberapa NGO dari dalam maupun luar negeri memperoleh hasil yang nihil dalam pengembangan sabuk hijau (green belt). Sudah 11 tahun pasca Tsunami Aceh namun pertumbuhan mangrove masih lamban dan pertumbuhannya masih secara parsial dan tidak merata. Beberapa sistem penanaman bibit mangrove yang dilakukan oleh NGO kadangkala cenderung sembarangan dan tidak memperhatikan jarak tanam bibit mangrove.

Melihat gejala perusakan hutan mangrove untuk berbagai kepentingan tersebut maka perlu dilakukan pengelolaan hutan mangrove secara lestari. Untuk dapat melakukan pengelolaan hutan mangrove secara lestari diperlukan pengetahuan tentang nilai 
strategis dari keberadaan hutan mangrove yang bermanfaat bagi masyarakat sekitar. Pengelolaan sumberdaya kelautan berbasis masyarakat merupakan salah satu strategi pengelolaan yang dapat meningkatkan efisiensi dan keadilan dalam pemanfaatan dan pengelolaan sumberdaya alam. Selain itu strategi ini dapat membawa efek positif secara ekologi dan sosial. Pengelolaan sumberdaya alam khususnya sumberdaya kelautan berbasis komunitas lokal sangatlah tepat diterapkan di Indonesia, selain karena efeknya yang positif juga mengingat komunitas lokal di Indonesia memiliki keterikatan yang kuat dengan daerahnya sehingga pengelolaan yang dilakukan akan diusahakan demi kebaikan daerahnya dan tidak sebaliknya. Berangkat dari asumsi bahwa laut tidak semata merupakan sebuah sistem ekologi, tetapi juga sistem sosial. Karena itu, pengembangan kelautan dengan memper-hatikan sistem ekologi-sosial mereka yang khas menjadi penting. Kuatnya institusi lokal di pesisir merupakan pilar bangsa bahari. Bila mereka berdaya, aturan lokal mereka bisa melengkapi kekuatan hukum formal, mereka bisa menjadi pengawas laut yang efektif, menjadi pengelola perikanan lokal karena didukung pengetahuan lokal (traditional ecological knowledge), serta pendorong tumbuhnya ekonomi pesisir.

\section{Permasalahan}

Kecamatan Kuala Bubon mempunyai mempunyai hutan mangrove yang luas yang tersebar di sepanjang pesisir Kuala Bubon. Pesisir Kuala Bubon merupakan tempat aktivitas perikanan yag mencolok dimana hutan mangrove menyediakan berbagai manfaat untuk memenuhi kebutuhan ekonomi masyarakat lokal. Kapal perikanan dan kegiatan transaksi serta pengolahan terjadi di sekitar pesisir Kuala Bubon yang menjadi jantung perekonomian Kabupaten Aceh Barat.

Berdasarkan hasil survei bahwa masih banyak siswa/siswi SMAN 1 Samatiga belum memiliki pengetahuan terkait dengan peranan ekosistem mangrove Kuala Bubon yang berada di sekitar mereka. Berbagai bentuk eksploitasi hutan mangrove mulai dari konversi lahan hutan mangrove menjadi lahan tambak, kebutuhan kayu api dan kebutuhan ekonomi menyebabkan ekploitasi yang tidak terkendali. Oleh karena itu, kegiatan sosialisasi sangat penting dilaksanakan kepada generasi millenial untuk menjaga kelestarian ekosistem mangrove.

\section{Tujuan Pelaksanaan} berikut :

Tujuan pelaksanaan kegiatan pengabdian kepada masyarakat ini adalah sebagai

1. Untuk mengamati kondisi kawasan hutan mangrove di Kecamatan Samatiga.

2. Untuk memberikan pemahaman kepada siswa/siswi SMAN 1 Samatiga tentang konservasi hutan mangrove.

3. Untuk membentuk kelompok konservasi hutan mangrove sebagai bentuk keberlanjutan program.

\section{Manfaat Kegiatan}

Masyarakat sasaran dalam kegiatan pengabdian terencana ini adalah siswa/siswi SMAN 1 Samatiga. Sekolah tersebut dijadikan sasaran kegiatan pengabdian karena sekolah tersebut berdekatan langsung dengan kawasan hutan mangrove sehingga sangat tepat untuk dijadikan masyarakat sasaran. Manfaat kegiatan ini antara lain : 
1. Masyarakat pesisir memahami konservasi mangrove agar ke depan mereka menjaga kelestarian ekosistem mangrove secara berkelanjutan.

2. Menanamkan kepedulian kepada generasi muda untuk menjaga kelestarian Ekosistem Mangrove.

3. Menumbuhkembangkan kegiatan konservasi ekosistem mangrove untuk menunjang perekonomian masyarakat.

\section{METODE PELAKSANAAN}

\section{Tempat dan Waktu}

Pelaksanaan kegiatan ini telah dilaksanakan pada tanggal 5 November $2018 \mathrm{di}$ SMAN 1 Samatiga Kecamatan Samatiga Kabupaten Aceh Barat Propinsi Aceh (Gambar 3). Kegiatan kegiatan pengabdian kepada berupa sosialisasi pengenalan hutan mangrove kepada siswa/siswi SMAN 1 Samatiga dan kegiatan eksplorasi hutan mangrove bersama siswa/siswi.

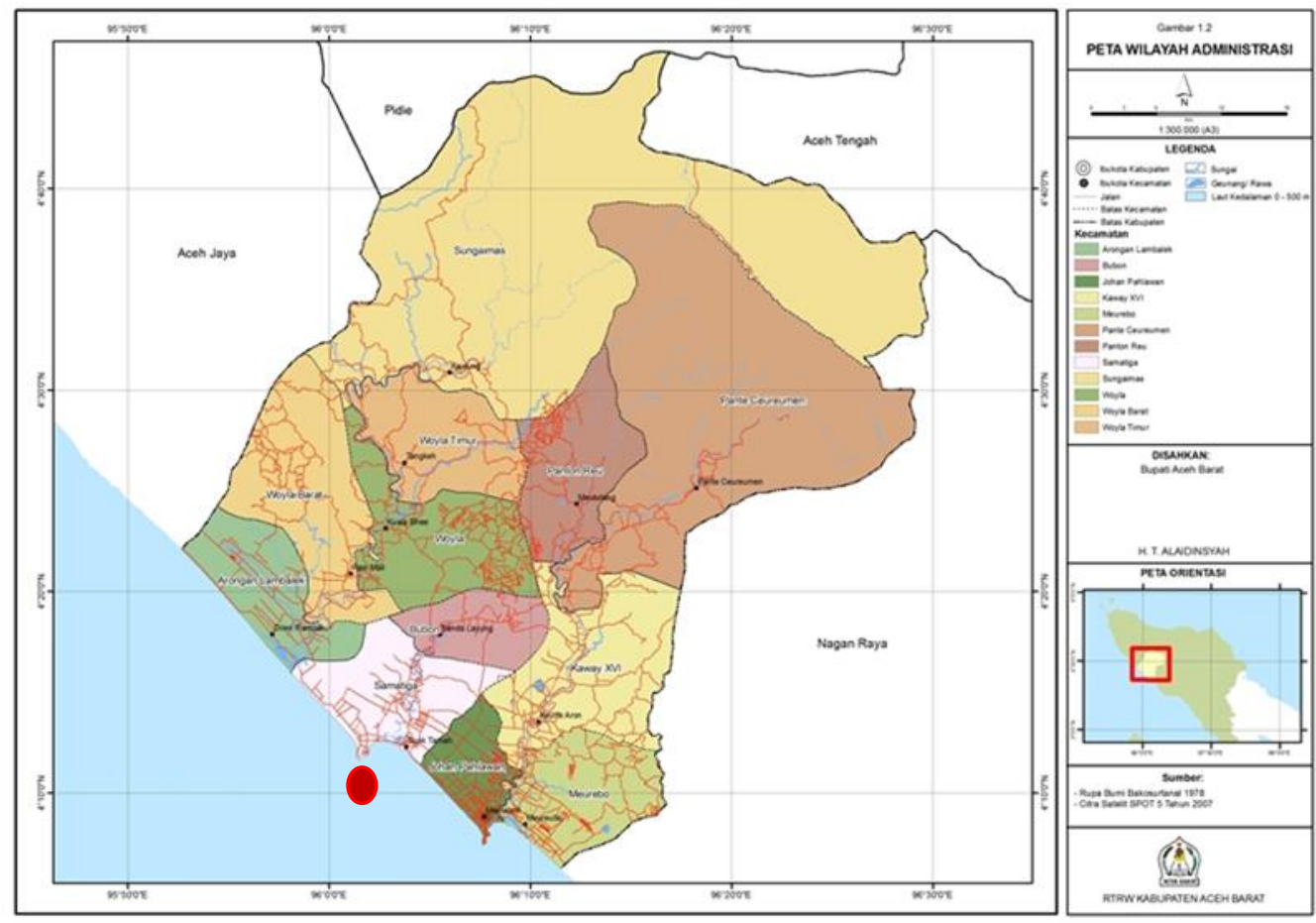

Gambar 1. Peta Lokasi Kegiatan Pengabdian kepada Masyarakat (O) Sumber : BPS Aceh Barat, 2015

\section{Teknik Pelaksanaan}

Metode pelaksanaan dengan menggunakan teknik penyuluhan secara langsung yaitu sosialisasi peranan hutan mangrove pesisir Kuala Bubon kapada siswa/siswi SMAN 1 Samatiga merupakan bentuk edukasi sangat tepat untuk menumbuhkan kesadaran masyarakat pesisir dan generasi muda dalam mempertahankan ekosistem mangrove tetap lestari. Adapun tahapan pekerjaan dalam 
menyelesaikan permasalahan dan sekaligus pencapaian tujuan program adalah sebagai berikut :

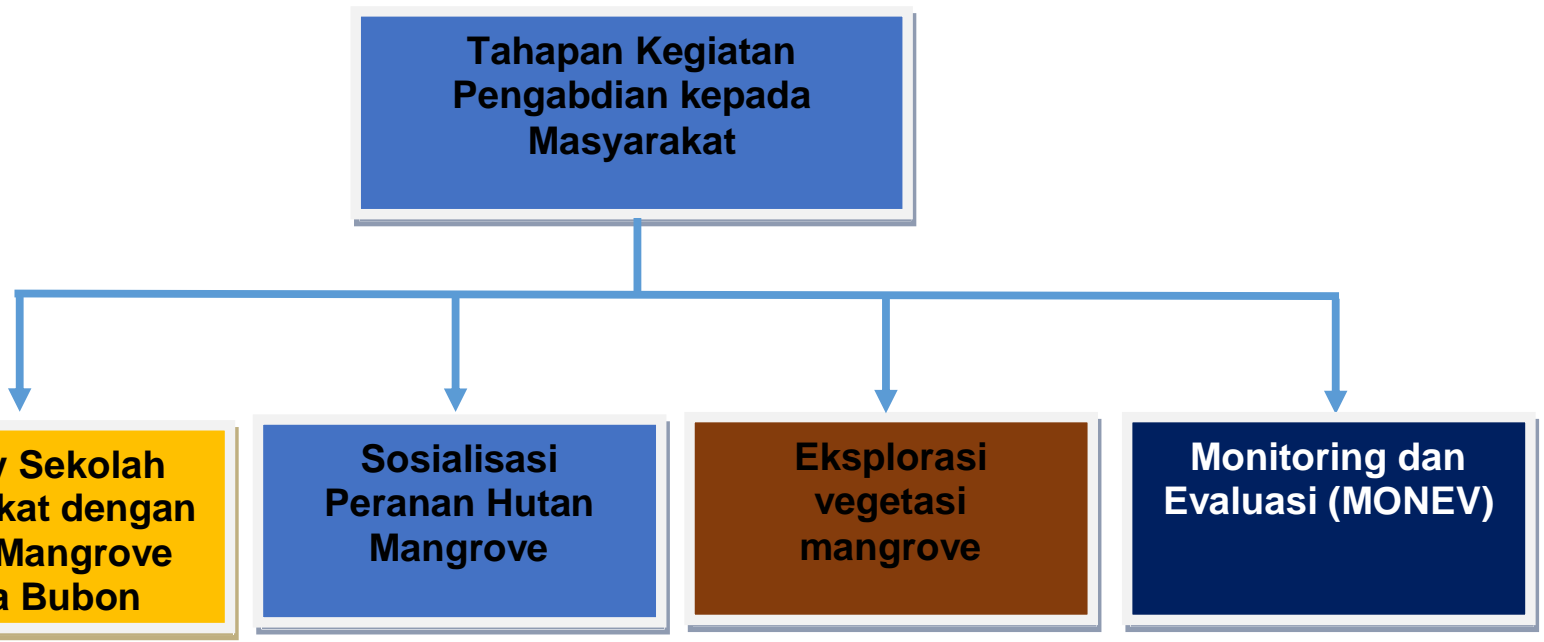

Gambar 2. Tahapan Pelaksanaan

\section{HASIL DAN PEMBAHASAN}

\section{Sosialisasi/Brainstorming Konservasi Hutan Mangrove}

Sosialisasi/brainstorming konservasi hutan mangrove dilaksanakan pada tanggal 25 September 2018 di Sekolah Menengah Atas Negeri (SMAN 1) Samatiga Kabupaten Aceh Barat. Materi yang disampaikan berupa pengenalan spesies mangrove wilayah Samatiga, gambaran umum konservasi hutan mangrove dan pemanfaatan ekosistem mangrove secara berkelanjutan. Upaya menjaga kelestarian hutan mangrove dapat dilakukan melalui teknik silvofishery dan pendekatan bottom up dalam upaya rehabilitasi hutan mangrove akibat kerusakan. Silvofishery merupakan teknik pertambakan ikan dan udang yang dikombinasikan dengan tanaman kehutanan dalam hal ini adalah vegetasi hutan mangrove. Usaha ini dilakukan guna meningkatkan kesejahteraan masyarakat sekitar hutan dan memelihara ekosistem hutan mangrove sehingga terjaga kelangsungan hidupnya.

Kegiatan sosialisasi/brainstorming konservasi hutan mangrove melibatkan siswa/siswi SMAN 1 Samatiga sebagai sasaran masyarakat pesisir yang ada di wilayah Samatiga. Siswa/siswi sangat antusias mengikuti kegiatan sosialisasi yang diselenggarakan oleh dosen Prodi IImu Kelautan FPIK-UTU (Gambar 3).

Dalam melaksanakan program PMMT ini, pengusul memberikan materi yang tepat sesuai dengan kurikulum sekolah menengah atas. Hal ini bertujuan agar proses transformasi ilmu pengetahuan tentang konservasi hutan mangrove berjalan dengan lancar. Dalam presentasi pada sosialisasi konservasi hutan mangrove, pengusul memberikan penjelasan detail tentang deskripsi hutan mangrove dan manfaat yang dapat diambil dari hutan mangrove itu sendiri (Gambar 3). 


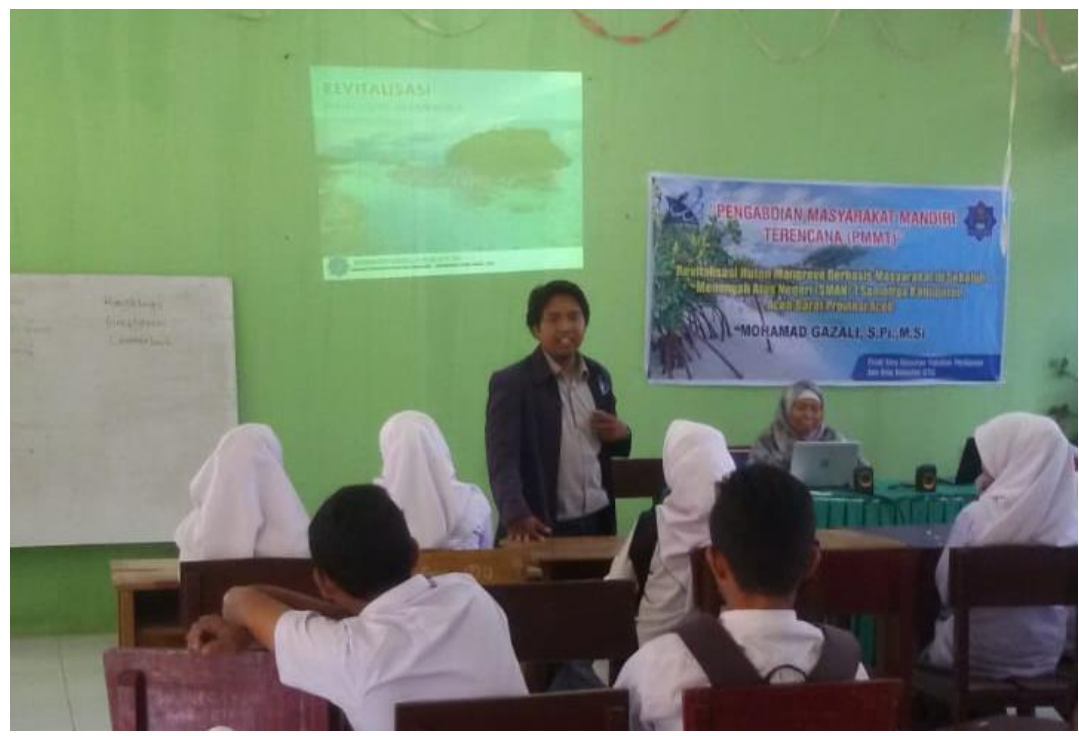

Gambar 3. Siswa/Siswi SMAN 1 Samatiga sangat antusias

\section{Eksplorasi Teknis Ekosistem Mangrove}

Kegiatan survey lapangan dan eksplorasi ekosistem mangrove langsung di kawasan hutan mangrove Samatiga. Hal ini bertujuan untuk memperkenal secara langsung tentang ekosistem mangrove kepada siswa/siswi dan bimbingan teknis dengan memberikan penyuluhan dalam proses pembibitan mangrove. Hal ini diawali dengan mencari buah/hipokotil mangrove yang dapat dijadikan sebagai anakan hutan mangrove (Gambar 5).

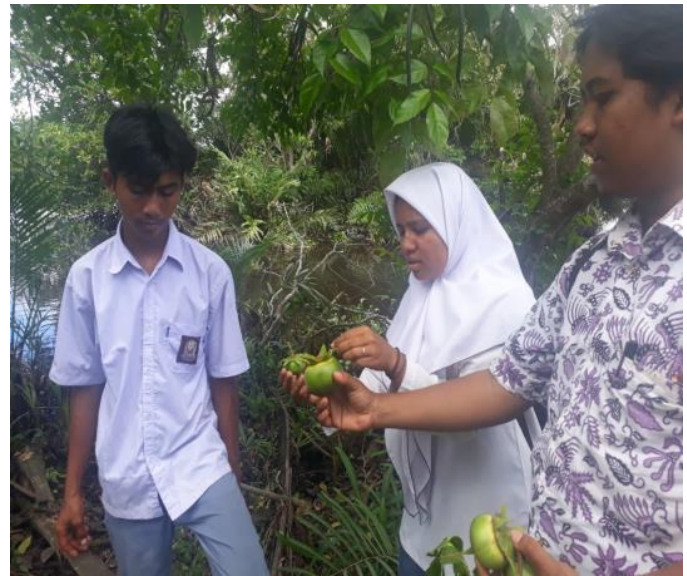

(a)

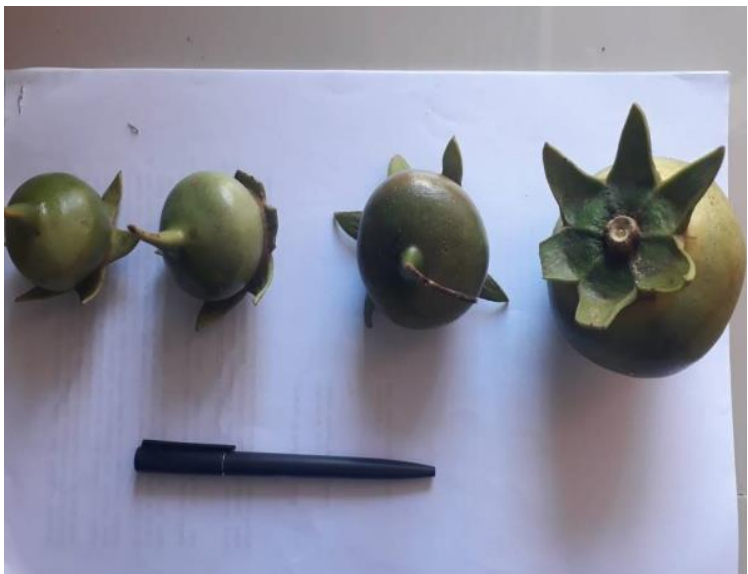

(b)

Gambar 5. (a). Penyuluhan mangrove Sonneratia alba, dan (b). Buah mangrove Sonneratia alba asal pesisir Samatiga 


\section{SIMPULAN DAN SARAN \\ Simpulan}

Berdasarkan hasil dan pembahasan di atas disimpulkan bahwa kegiatan pengabdian kepada masyarakat meliputi sosialisasi peranan hutan mangrove Kuala Bubon sebagai upaya menumbuhkan kesadaran bagi siswa/siswi SMAN 1 Samatiga. Selanjutnya, kami melaksanakan studi lapangan dengan mengidentifikasi spesies mangrove yang ada di Sekitar Pesisir Kuala Bubon. Dalam kegiatan pengabdian kepada masyarakat tersebut berjalan dengan baik dan lancar. Siswa/siswi begitu antuasias mengikuti program pengabdian kepada masyarakat dan mendapat dukungan penuh dari pihak sekolah SMAN 1 Samatiga.

\section{Saran}

Perlu adanya sosialisasi pengenalan penyu di Sekolah lainnya yang berdekatan dengan kawasan ekosistem mangrove agar kegiatan sosialisasi tersebut tersebar merata di wilayah kawasan konservasi hutan mangrove.

\section{UCAPAN TERIMA KASIH}

a. Dalam mensukseskan kegiatan pengabdian kepada masyarakat ini tidak terlepas dari kerjasama yang baik dari Mahasiswa FPIK yang mendampingi dalam proses kegiatan Pengabdian kepada Masyarakat.

b. LPPM UTU yang memberikan izin berupa surat tugas pelaksanaan pengabdian kepada masyarakat sehingga kegiatan tersebut berjalan dengan lancar.

c. Kepada pihak SMAN 1 Samatiga yang memfasilitasi penggunaan fasilitas sekolah untuk kegiatan sosialisasi peranan hutan mangrove.

\section{DAFTAR PUSTAKA}

Badan Pusat Statistik, 2013. Aceh Barat Dalam Angka

Environmental Justice Foundation. 2004. Mangrove Nature Defence Against Tsunami (A report on the impact of mangrove loss and shrimp farm development on coastal defences). London (UK)

Noor YR., Khazali M, Suryadiputra NN. 2006. Panduan Pengenalan Mangrove di Indonesia. Wetland International Indonesia Programme. Bogor

Mann, K.H. 1982. Ecology of Coastal Waters. A Systems Approach. Studies in Ecology, Vol. 8, Blackwell Scientific Publications, 322 hal. 